desde la academia

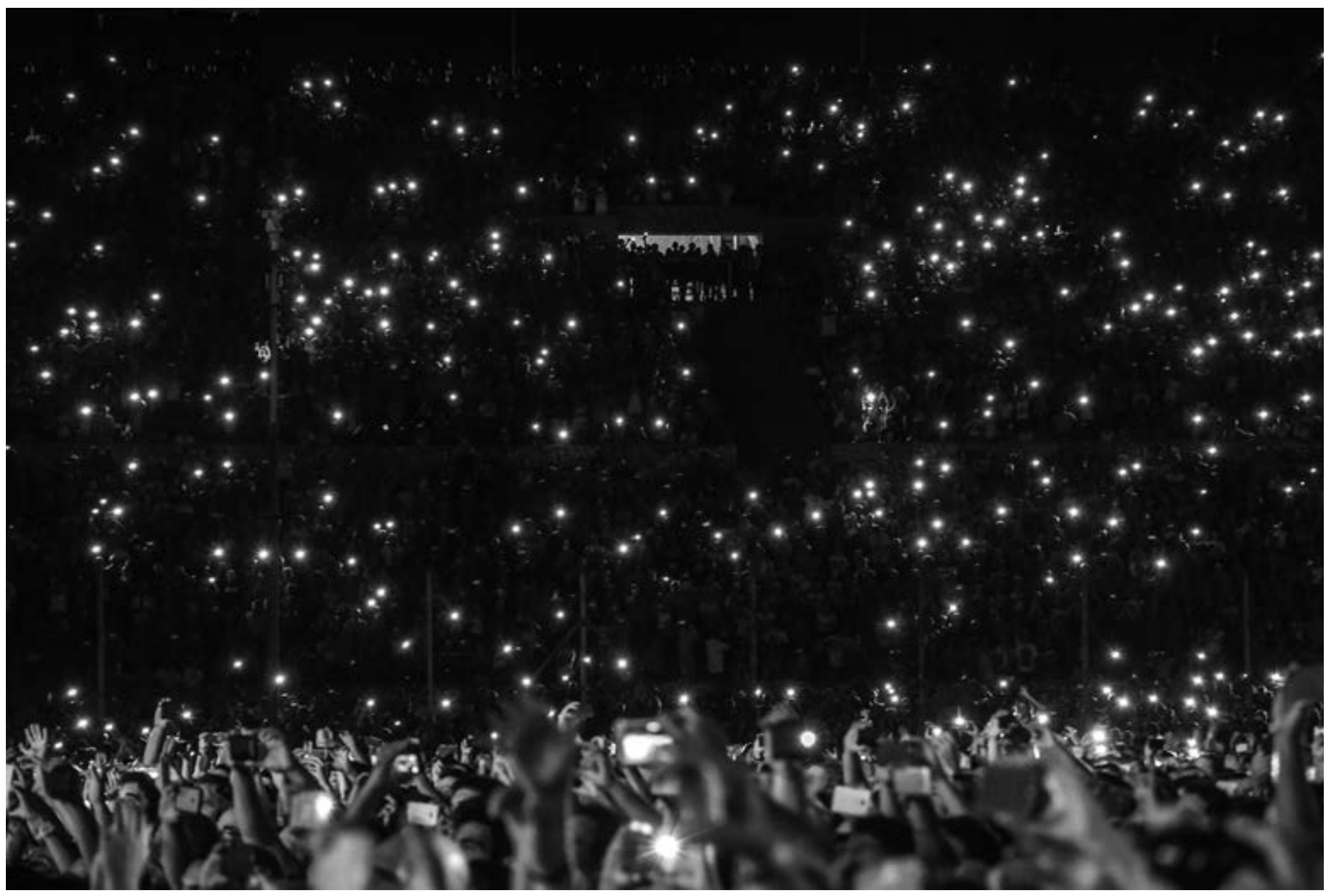

Foto: Pablo Porciúncula

\title{
Estética de cercanía, un lazo entre el fotoperiodismo y la representación de la realidad
}

Aesthetic of closeness, a link between photojournalism and representation of reality

https://doi.org/10.22235/d.v0i25.1270

Pablo Porciúncula y Florencia Varela 


\section{RESUMEN}

El objetivo de este artículo es analizar los cambios que ha experimentado la práctica fotoperiodística debido a la incorporación de dispositivos y recursos digitales por parte de los medios de comunicación. La principal hipótesis es que se ha producido una estética de cercanía, concepto con que se denomina a la presentación de productos audiovisuales realizados por fotógrafos profesionales que introducen una estética amateur o utilizan medios no profesionales. Este trabajo da cuenta del advenimiento de esta estética de cercanía y sus principales estrategias formales, con el fin de analizar el estatus actual de la fotografía en su relación con la representación de la realidad. El análisis se sustenta sobre algunos abordajes periodísticos, seleccionados en función de su relevancia, y en cuestionarios realizados a los responsables del contenido multimedia de cuatro medios uruguayos.

Palabras clave: fotoperiodismo, prensa, representación, imágenes amateur

La realidad es más real en blanco y negro Octavio Paz (1976)

En octubre de 2012, la directora de fotografía de la revista Time, Kira Pollack, contrató a cinco fotógrafos para cubrir en Instagram los efectos del huracán Sandy, que azotaba el este de Estados Unidos. Según comenta Pollack, la cobertura realizada por los fotógrafos Michael Christopher Brown, Benjamin Lowy, Ed Kashi, Andrew Quilty y Stephen Wilkes, fotoperiodistas premiados y muy activos en Instagram, fue una de las más populares de la revista: su cuenta atrajo a 12.000 nuevos seguidores en las 48 horas siguientes.

\section{ABSTRACT}

This article aims to analyze the changes in the photojournalistic practice because of the incorporation of digital media. A first hypothesis is an aesthetic of closeness, a concept that refers to the presentation of photographs or audiovisual products made by professional photographers who introduce an amateur aesthetic or use nonprofessional media. The objective is to explore some of the keys to the advent of this aesthetic of closeness and its main formal strategies, in order to analyze the current status of photography in its relationship with the representation of reality. The analysis is based on data from a limited sample probe taken at some journalistic approaches selected and questionnaires made those responsible for the multimedia content of four uruguayan media.

Keywords: photojournalism, press, representation, amateur images

Pollack atribuye su decisión a la necesidad de una cobertura más inmediata, una de las características principales de esa plataforma. Esta decisión contribuye a un proceso que ya a esas alturas parece no tener marcha atrás: "el mismo equipo y plataformas que habían sido adoptados por el periodismo ciudadano habían sido aceptados por el mundo de la fotografía profesional" (Scott, 2015, p. 74).

La inmediatez es una de las razones fundamentales que han llevado a distintos medios uruguayos como Espectador.com, Portal180 e incluso medios de prensa tradicionales como El País, a través de su portal web, a incorporar en los años recientes fotografías tomadas con celulares, tanto de fotoperiodistas como de usuarios.
Pablo Porciúncula Universidad Católica del Uruguay Montevideo, Uruguay pablo.porciuncula@afp.com

Florencia Varela Universidad Católica del Uruguay Montevideo, Uruguay fvarelag@ucu.edu.uy

Recepción: noviembre 2015 Aceptación: abril 2016 
"Generalmente usamos las fotografías de los lectores en fenómenos climáticos, accidentes, situaciones puntuales en las que el lector está en el lugar de los hechos y nosotros no", explica Florencia Traibel, editora multimedia de El País. "Son más vinculadas con la inmediatez del hecho" (F. Traibel, comunicación personal, noviembre 6, 2015).

Aunque, tal como afirma Pollack, el periodismo ciudadano es uno de los ámbitos fundamentales de los que se nutre la práctica fotoperiodística actual, se debe considerar también la llamada fotografía vernácula. Es decir, aquellas imágenes que forman parte de la producción fotográfica en general, definida en palabras del investigador Clément Chéroux como la otra fotografía, aquella que no tiene intenciones explícitamente artísticas, que no pertenece a la fotografía periodística profesional, pero tampoco está destinada a permanecer en el recinto privado del álbum familiar. En este sentido, muchas de las fotografías que se publican actualmente en Internet parecen coincidir con esta fotografía a la que Chéroux describe como otra (citado en Aguilar, 2015).

Millones de fotografías se producen a diario en el mundo, giran sobre él, lo muestran, lo miran. Una gran parte de esta inmensa producción registra la vida diaria y la exhibe: viajes, conciertos, celebraciones, hitos familiares o hechos insólitos. Los momentos banales como el desayuno diario, un encuentro furtivo o el paisaje frecuente que asoma a la ventana se disputan los primeros lugares con el registro de otros hechos de interés social e internacional, que también son captados por las lentes de ciudadanos comunes y divulgados a escala planetaria. En medio de este remolino de imágenes, la práctica fotoperiodística ha sufrido transformaciones y ha desarrollado lo que definimos como estética de cercanía. Esta se sustenta en la convivencia, en los medios de prensa, de imágenes producidas tanto por profesionales como por aficionados: presenta fotografías o productos audiovisuales realizados por fotógrafos profesionales, pero con una estética amateur o utilizando medios no profesionales.
La estética de cercanía busca empatizar visualmente con los lectores y sostener su mirada al utilizar códigos del lenguaje visual que les son familiares, con el agregado de que las imágenes recuperan la credibilidad que otrora aportaban per se las imágenes profesionales, al ser percibidas como documento.

La decisión de Pollack forma parte de un conjunto de acciones emprendidas por distintos medios de todo el mundo para adaptarse a estos nuevos procesos de comunicación y recepción. Otro ejemplo es la foto de Instagram realizada por el fotógrafo Nick Laham, publicada en la portada impresa del periódico The New York Times el 31 de marzo de 2013, en la que se retrataba a Alex Rodríguez, uno de los más legendarios y controvertidos jugadores de béisbol. ${ }^{1} 0$ el especial en que los fotógrafos de la Agence France Presse (AFP) registraron con iPhones sus actividades durante la Copa de Confederaciones FIFA en Brasil, en junio de 2013. Más recientemente, en marzo de 2016, los retratos que la fotógrafa Valerie Macon realizó para la prensa, con su Polaroid, de los deportistas estadounidenses que competirían en los Juegos Olímpicos de Brasil.

Algo similar sucede en el contexto local: si bien desde mediados de la década del 90 una gran parte de los medios ya habían inaugurado portales online, es en estos últimos años en los que se producen cambios significativos respecto a la preocupación por la imagen y los contenidos multimedia. El impulso de estrategias relacionadas con la inclusión de fotografías amateurs se desarrolla también en los productos que los medios presentan en sus portales de Internet.

En la prensa uruguaya, en particular en El Observador y El Pais, se incorporaron secciones como $L a$ semana en Instagram, así como pequeños videos con un tratamiento de imagen básico (plano secuencia o planos de corta duración y cámara fija), acompañados o no con una locución informativa. 
En algunas ocasiones, además, se incorporan fotografías o videos de los usuarios. Estos ejemplos permiten constatar la adopción de recursos no profesionales -o por lo menos ajenos a la práctica fotoperiodística ortodoxapor parte de los medios de comunicación en primer lugar, pero también de los periodistas. La incidencia de las prácticas fotográficas amateurs, provenientes tanto del ámbito doméstico y social como del actual periodismo ciudadano, marca una tendencia e impulsa la adopción de nuevos recursos formales que redefinen las estrategias mediales de representación de la realidad.

\section{Fotoperiodismo y actualidad}

La importancia de la imagen en los medios de prensa ha ido en aumento y se ha acelerado con las nuevas tecnologías y formatos digitales ${ }^{2}$. En los medios de Uruguay se ha producido en los últimos años un incremento de la presencia de la imagen, ya sea fija o de video. La adaptación a Internet como medio determinado por la pantalla y los contenidos multimedia, así como la necesidad de mantener al lector el mayor tiempo posible en un portal o una nota, han contribuido a esta circunstancia.

Mauricio Erramuspe, jefe de contenidos de Portal180, afirma que los videos "aumentan el tiempo en que el usuario permanece en un portal" (comunicación personal, noviembre 10, 2015). Estas nuevas posibilidades y exigencias del multimedia y de las webs son en parte responsables de algunas modificaciones producidas en la práctica tradicional del periodismo y, en particular, del fotoperiodismo. La celeridad de estos cambios exige reflexiones para repensar el rol de la fotografía de prensa profesional.

Este trabajo analiza el advenimiento de esta estética de cercanía, así como sus principales estrategias formales, cada vez más presentes en la práctica fotoperiodística. Para ello, se toman como base algunos datos empíricos en el ámbito del fotoperiodismo internacional, así como los resultados de un cuestionario en línea realizado a los editores multimedia de los diarios El País y El Observador; al editor de Espectador.com (la plataforma online de la radio El Espectador) y al editor de Portal180, un medio informativo $100 \%$ digital.

La preocupación por la práctica fotoperiodística está relacionada, entre otras cosas, con las transformaciones que la afectan y obligan a redefinirla. Los cambios provocados por la fotografía digital y la masificación de la producción de fotografías parecen haber sumergido a los fotógrafos profesionales en tiempos de incertidumbre laboral, pero también los libera de antiguas posturas a las que debian responder. La relación del fotógrafo profesional con su oficio parece estar en cuestión en tiempos en que el fotógrafo amateur se ha apropiado del lenguaje audiovisual: piensa en imágenes, lee imágenes, produce imágenes, se comunica con imágenes y sostiene sus relaciones con imágenes. El gesto de fotografiar se ha vuelto un acto compulsivo. Muchos estudios incluso consideran al fotoperiodismo como una profesión difícil de delimitar, debido a que no es posible excluir de su campo profesional al fotógrafo aficionado (Mäenpää, 2014, p. 93).

La relación del fotoperiodista con la práctica fotográfica ha estado siempre determinada por los medios: "el diario y la revista serán el lugar en el que se generen condiciones" para esta actividad, escribe Margarita Ledo (1998, p. 21). Los medios determinan en todo momento el tratamiento que se debe dar a la imagen, que en ocasiones puede estar guiado por un criterio periodístico y, en otras, por criterios comerciales. La imagen también obliga a los medios a adaptarse.

El periodismo gráfico debió introducir importantes transformaciones en la manera de presentar la información y aprovechar los recursos visuales, de tal forma que en la actualidad un diario no solo es confeccionado para ser leído sino también para ser visto (Minervini y Pedrazzini, 2004, pp. 1 -2).
2:: En marzo de 2010, Francis Kohn, director para América Latina de la Agence France Presse (AFP), presentó los resultados de una encuesta entre los clientes de AFP en la que concluye que las "agencias internacionales -todas- son imagen o no son". Los productos periodísticos a los que las agencias internacionales apuestan tienen a la imagen como centro, desplazando la palabra a un segundo plano (Porciúncula, 2010, p. 4). 


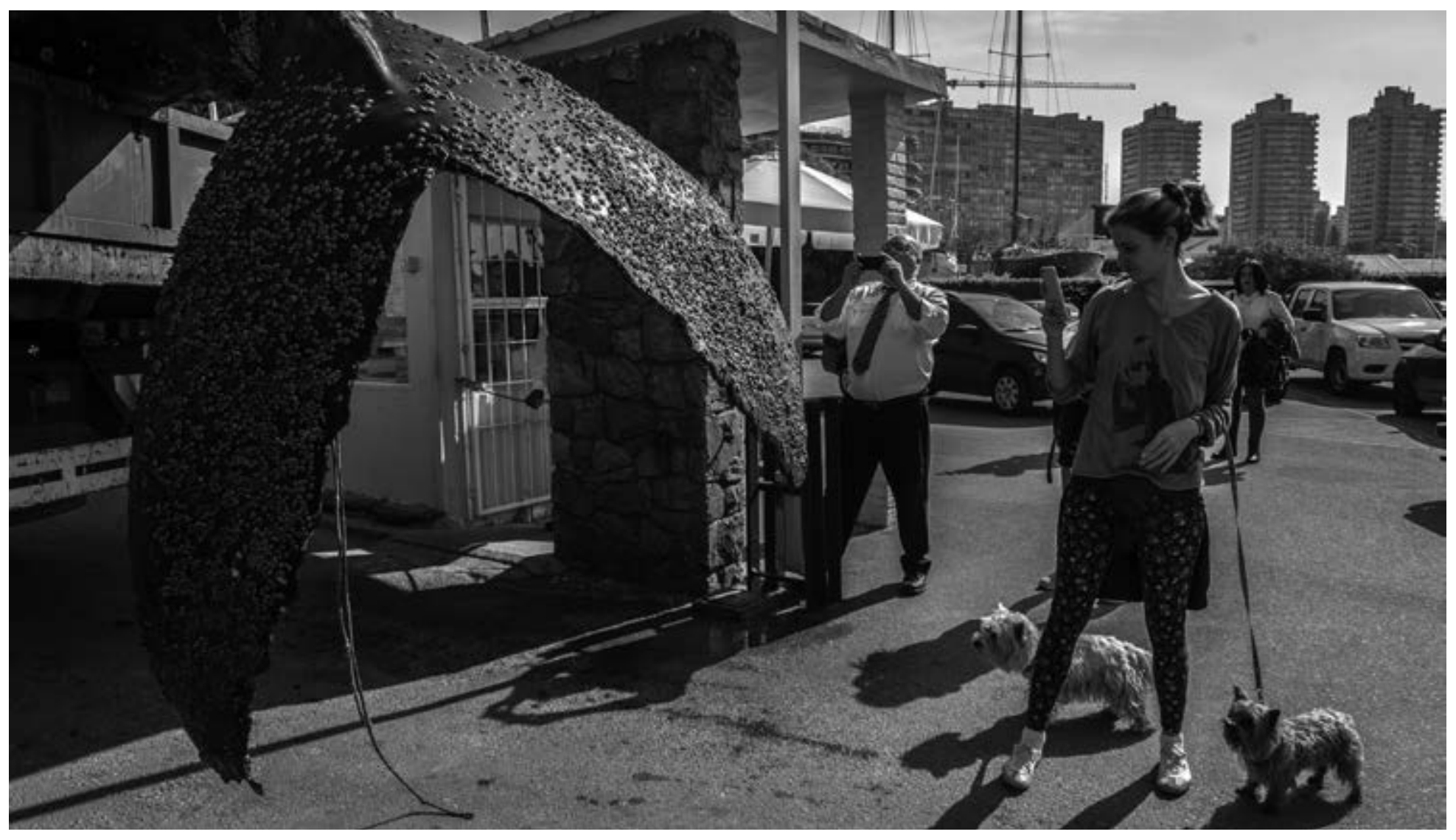

Foto: ${ }^{\circ}$ AFP / Pablo Porciúncula. El cadáver de una ballena es trasladado

tras ser removido de la costa del Puerto del Buceo en Montevideo, agosto de 2016
A demanda de las empresas de comunicación, los fotógrafos pasaron del blanco y negro al color, de la película al formato digital, de la imagen técnicamente especializada a la incorporación de recursos amateurs, e incluso se vieron obligados a incorporar el lenguaje audiovisual. Este último es posiblemente el cambio más profundo que la era digital impone a la relación del fotógrafo con la fotografía.

La necesidad de los medios de crear productos multimedia y el desarrollo tecnológico de las cámaras fotográficas, que permiten el registro de sonidos y video, crean el marco adecuado para el contacto del fotógrafo con el lenguaje audiovisual. Un lenguaje que comparte códigos con el fotográfico, pero que también se contrapone. Basta pensar en la necesidad secuencial de la imagen en video y contrastarla con la absoluta soledad con la que una fotografía se sostiene. 0 pensar que, mientras que en la fotografía, tal como plantea Roland Barthes, "hay una doble posición conjunta: de realidad y de pasado", cuyo distintivo es "esto ha sido" (1990, p. 136), la imagen en movimiento se comporta más como un presente. Trabajar en un mismo producto con estas variaciones de lenguaje, más las que aporta el sonido, es uno de los principales desafíos por los que se ve atravesada la práctica fotoperiodística actual. El reportero fotográfico deviene en un reportero visual, moldeado por múltiples lenguajes.

Pero si la incorporación de secuencias de video le exige al fotógrafo sumergirse en un lenguaje visual nuevo, el empleo de recursos amateur -a demanda de los medios y de la coyuntura social respecto a la masificación de los dispositivos de generación de imágenes- es quizá uno de los mayores desafíos que afectan a la definición de la profesión. Algunos medios justifican la decisión de incorporar estos recursos, así como las fotografías de aficionados, con el argumento de querer mejorar el servicio público que ya de por sí es parte de la profesión del periodismo (Mäenpää, 2014, p. 93). “[Buscamos] más ojos y oídos en todos lados. Ideas y puntos de vista diversos", apunta Carina Novarese, editora de contenidos multimedia de El Observador (comunicación personal, noviembre 7, 2015). Buscar mayor empatía con los lectores, o lograr más cercanía e incrementar la participación de los usuarios, como apuntan José Frugoni (Espectador.com) y Mauricio Erramuspe (Portal 180), son otras de las razones que justifican estas estrategias. Son fotografías que aportan inmediatez y un vínculo con el lector, sostiene Traibel (El País). 
Se denomina entonces como estética de cercanía al conjunto de acciones desarrolladas por los medios, que parten de apropiarse de herramientas comunicativas utilizadas por sus lectores con el objetivo de mantenerse en relación con estos. Los medios amoldan la firma de sus discursos a una estética y lenguaje familiar para sus receptores. En el desarrollo de esta estética de cercanía los medios no dudan en reproducir el tipo de fotografías generadas por sus usuarios ni en generar espacios para que las fotos de estos aparezcan publicadas. Se trata de una fotografía con menos exigencia técnica, según los parámetros clásicos, y que cuenta siempre con la posibilidad de ser parte de una secuencia en la que se estructura una narrativa. Este uso no es exclusivo para las fotografías, sino para las imágenes en general.

Unas de las imágenes más difundidas sobre los atentados a París en noviembre de 2015 fueron las tomadas por el periodista Daniel Psenny, de Le Monde, desde la ventana de un apartamento detrás del teatro Bataclan. Psenny filma con su celular, en posición vertical, la huida de varias personas, algunas de ellas heridas. La cámara recorre la calle de derecha a izquierda y vuelve hacia la otra dirección. Se escuchan gritos y sobre todo la voz del periodista preguntando una y otra vez “¿qué sucede?”. En algún momento se ve alguien aferrado a una ventana, colgando al vacío; también se distingue otra persona que se detiene en el umbral de la ventana y desde allí le habla e intenta asirla. No se registra el desenlace de la situación. Ninguna de las historias que se suceden en esa calle queda narrativamente concluida, y la grabación termina abruptamente. Sin embargo, la carencia de estructura narrativa parece agregarle valor de autenticidad al video, le da credibilidad y le otorga el estatus de documento. La grabación en vertical y la falta de definición de las imágenes se tornan recursos clave en la interpretación del grado de verdad de esta secuencia, aunque sea discutible su valor informativo. La legitimidad de estas imágenes, en tanto reflejo de la realidad, se solventa en parte en esta estética de cercanía que remite al usuario a una experiencia similar a cuando él mismo graba con su celular de forma no profesional.

No obstante, en la actualidad, estas imágenes se perciben más fieles a la realidad de los acontecimientos que muchas de las realizadas con el estilo profesional. De las dos funciones de la fotografía de prensa señaladas por distintos autores, aquella que la posiciona como testimonio de lo acontecido parece haber ganado terreno respecto de la descriptiva (Minervini y Pedrazzini, 2004, p. 3). En este sentido, estas imágenes amateurs constituyen una prueba de veracidad que el medio pone a disposición del usuario. En lo que refiere a los dispositivos no profesionales, como el iPhone, su programación automática diseñada para todo tipo de usuario reduce las posibilidades de control de la fotografía por parte del profesional, lo que garantiza en cierta forma la espontaneidad del registro, un gesto más cercano al usuario que al profesional. Como bien lo expresa Víctor del Río (2008) en referencia al efecto de realidad: "el cámara no profesional se nos acerca como modelo identificativo, y el fenómeno, aparentemente ajeno a la construcción periodística de la noticia, adquiere mayores dosis de realidad" (p. 132).

Los usuarios parecen mostrarse cómodos con las imágenes que se enmarcan en una estética de cercanía. También han aprendido del valor que tienen para los medios. Prueba de ello es la última de las tendencias, observada entre los vecinos del barrio Saint Dennis, en la periferia de París, que se volcaron a las calles a filmar con sus celulares apenas escucharon los primeros disparos durante los procedimientos que la Policía francesa realizó allí, tras los atentados del 13 de noviembre. Una vez que la Policía se retiró, esos vecinos llamaron a los medios para vender las imágenes que habían grabado. Recibían a los periodistas con sus celulares en mano para que pudieran visionar las imágenes y comprar las que fuesen de su agrado. 
Las imágenes amateurs son aceptadas como documento por el público, tanto si aparecen en las redes sociales como si lo hacen en un medio masivo, pero a los medios se les exigirá avalarlas como imágenes sin alteración, que se ajusten al hecho noticioso. En tiempos en que la inmediatez informativa es primordial, que la producción de imágenes es tan alta como su demanda, los medios están obligados a poner bajo la lupa una y otra vez las fuentes que proporcionan las imágenes. No solo para evitar posibles demandas económicas relacionadas al derecho de autor o al mal uso de las imágenes, sino también para cuidar su credibilidad, que está en juego con cada imagen que publica. Y la credibilidad es el valor supremo del periodismo.

El 19 de noviembre de 2015 se hizo público un correo electrónico que la agencia de noticias Reuters envió a sus colaboradores, en el que informaba sobre la prohibición de que las fotos se procesen en archivos $R A W^{3}$. Un portavoz de la agencia señaló que la decisión buscaba aumentar tanto la ética como la velocidad.

Como testigos oculares de los eventos cubiertos por los periodistas dedicados y responsables, Reuters Photos debe reflejar la realidad. Si bien nuestro objetivo para la fotografía es de la más alta calidad estética, nuestro objetivo es no interpretar artísticamente la noticias (Zhang, 2015).

3:: El formato RAW es el archivo de la imagen al ser tomada por la cámara fotográfica sin procesar, en bruto, mientras que el formato JPG archiva la imagen mediante un proceso de compresión cuyos valores no son suficientes para la corrección de la fotografía en lo referente a tonalidades, colores, iluminación, etcétera. por parte de los medios y la cada vez mayor especialización de la imagen publicitaria. Esta última se presenta "cada vez más sofisticada en sus estrategias persuasivas, en el desarrollo de retóricas visuales y de formas de simbolización, de excelente calidad formal” (p. 12). Baeza señala que el decrecimiento de la inversión por parte de los medios es uno de los principales problemas a los que se enfrenta el periodismo en la actualidad. Desde su punto de vista, además, los medios se las ingenian con estrategias de distinto tipo para "invisibilizar" algunas realidades: las leyes "cada vez más severas con el registro de imágenes" (Baeza, 2009, p. 12) son una excusa perfecta para este objetivo. Realidades que, tal como señala este autor, son sustituidas por personajes del espectáculo que llenan el vacío sufrido por los lectores de referentes identitarios, a la vez que atraen mayor inversión publicitaria. Algunas de estas acciones también afectan la legitimidad de la imagen documental y la sumergen aún más en la crisis desencadenada por el debilitamiento de su estatus de representación de la realidad.

La insistencia en una objetividad imposible contribuye a la sospecha que sobrevuela los documentos de prensa. "La fotografía siempre ha sido alterada, manipulada”, afirma el fotógrafo mexicano Pedro Meyer en una entrevista (Villarreal, 2014, p. 14). Sin embargo, es importante mencionar que gran parte de la legitimidad de la fotografía amateur se debe a la reproducción de forma indiscriminada, por parte del aficionado, de fórmulas mediáticas que se decodifican como “objetivas”. En este sentido Meyer lo expresa de forma contundente cuando afirma: "hoy todos somos fotógrafos, pero con una cultura visual escasa” (Villarreal, 2014, p. 13). Es decir que, si bien por un lado la estética de cercanía parece incluir la promesa de incorporar la mirada del usuario, así como de profundizar en la responsabilidad ética que asumen los medios acerca de la pluralidad en el tratamiento de los acontecimientos, por el otro lado puede estar simplemente reproduciendo de forma acrítica versiones estandarizadas de un mismo modo aprehendido de plasmar la realidad en imágenes. 

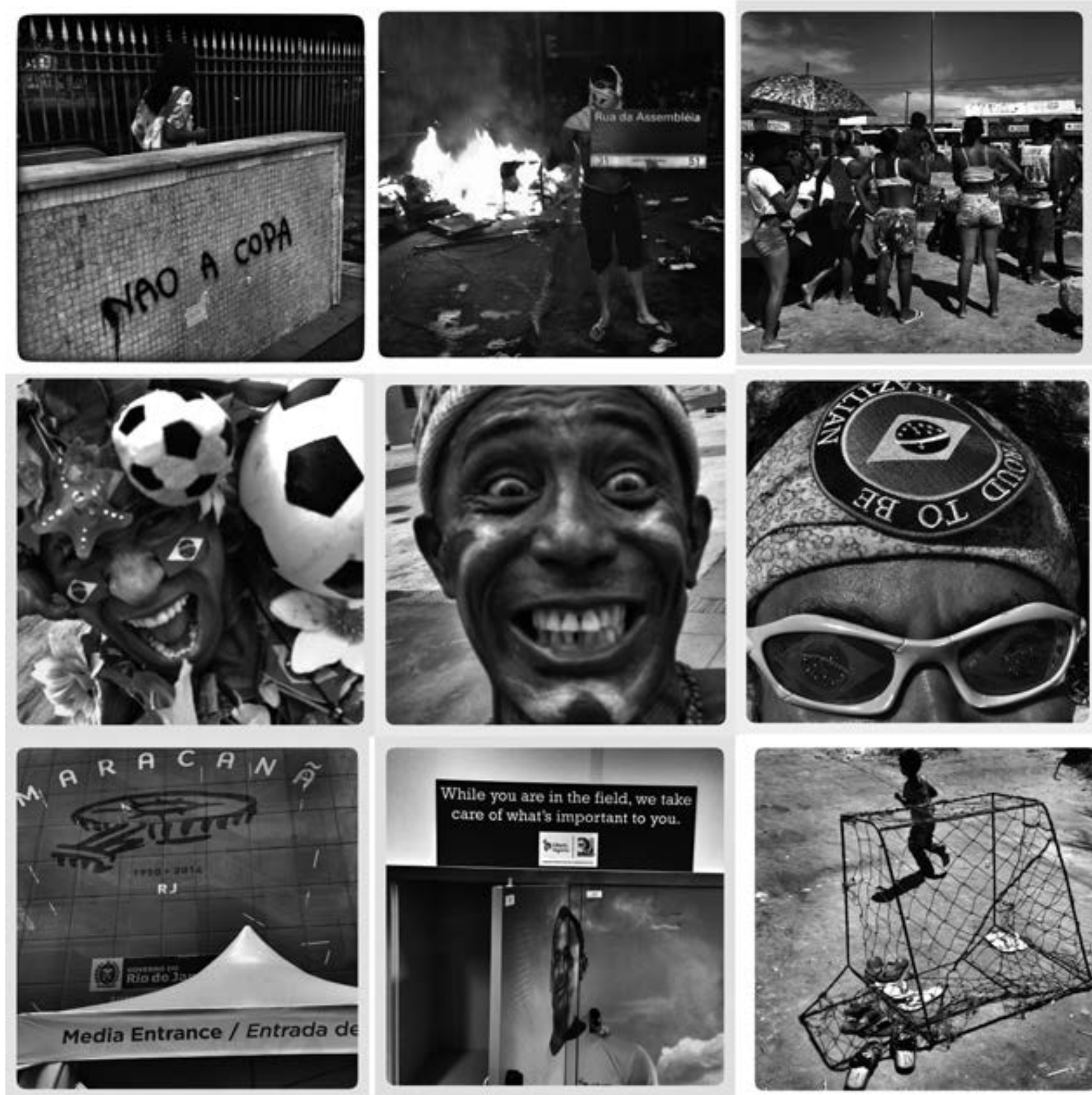
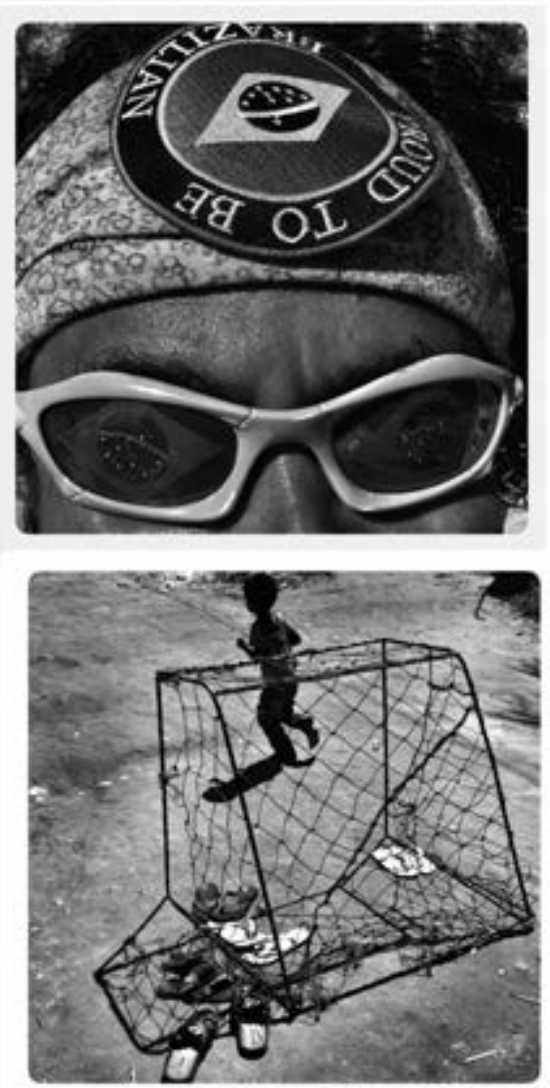

El fotoperiodismo transita un camino que podría calificarse como crítico, y que resulta de especial interés por la importancia cada vez mayor de la imagen en las coberturas noticiosas. Gran parte del acceso a la realidad local y planetaria se produce a través de los medios, lo que convierte a la imagen periodística en un potente espacio de mediaciones simbólicas en lo que respecta a las coordenadas de lo real. Pero la situación actual del fotoperiodismo se ve atravesada no solo por intereses económicos -tanto de los medios que redujeron su inversión en investigación como de los organismos protagonistas de los acontecimientos, que muchas veces cuentan con sus propios agentes de prensa- sino también por lo que autores como Baeza, Ledo o Ritchin califican de crisis de la imagen documental. Para Baeza, por ejemplo, esta crisis se debe en parte al "descrédito público hacia la propia fotografía como forma de documentar la realidad" (2009, p. 12). En este sentido, y siguiendo esta línea de pensamiento, redefinir la práctica fotoperiodística implica reconsiderar las estrategias de representación de la realidad.
Foto: ${ }^{\odot}$ AFP. Combo de fotografías tomadas por fotógrafos de AFP durante la Copa de las Confederaciones en Brasil, julio de 2013 


\section{La realidad y su representación}

Honesto sí, objetivo no

Eugene Smith (1948)

Desde las primeras imágenes materializadas por efecto de la luz y la sensibilidad del soporte, el dispositivo fotográfico ha estado asociado a la idea de ser huella de lo real. Así, y tal como resalta Fontcuberta (2003), la experiencia propiciada por la fotografía se emparenta con la mirada empírica del positivismo (p. 9). La representación de la realidad ha sido la principal preocupación y labor del fotoperiodismo: un asunto vinculado históricamente con la posibilidad de representación fiel que ofrece la fotografía. Ya desde la segunda mitad del siglo XIX, con el desarrollo de la técnica, la fotografía comienza a percibirse en el imaginario social como documento, en gran medida debido a los aspectos propios de una ejecución mecánica (Ledo, 1998, pp. 20-44).

Esta relación de la fotografía con la realidad será la base sobre la cual se instituya la idea de objetividad, comprendida como la posibilidad de la fotografía como medio, y del fotoperiodismo como práctica, de reproducir un acontecimiento de forma literal: exacto y completo, sin intervención significativa del fotógrafo, como un "mensaje sin código" (Barthes, 1986, p. 13). Ahora bien, esta relación entre fotografía y objetividad pronto quedaría relativizada. Así lo demuestran fotografías como las de Eugène Atget o Henri Cartier-Bresson que, influenciadas por una estética surrealista, reproducían la mirada propia del fotógrafo. "La fotografía es para mí el reconocimiento en la realidad de un ritmo de superficies, líneas o valores", escribe Cartier-Bresson: "el ojo recorta el tema y la cámara no tiene más que hacer su trabajo, que consiste en imprimir en la película la decisión del ojo" (2003, p. 230). La corriente estructuralista, así como los estudios semióticos de autores como Christian Metz, Roland Barthes, Umberto Eco o el Grupo $\mu$, entre otros, han sido decisivos en lo que Philippe Dubois (1994) describe como el desplazamiento de la capacidad de verdad empírica hacia el mensaje: "la foto se va a convertir en reveladora de la verdad interior" (p. 40).

A pesar del reconocimiento temprano de que la fotografía, además de ser un recorte del acontecimiento, es el resultado de las decisiones conscientes o inconscientes del fotógrafo, en el ámbito del fotoperiodismo la insistencia en una objetividad fundada en su capacidad de captura mecánica sentó las bases de una estética documental que garantizara una imagen neutra: "la fotografía ha sido vista como la herramienta ideal para el trabajo con las noticias que necesitan la evidencia como soporte de la pretensión de objetividad" (Mäenpää, 2014, p. 92). Pero esta estética documental va quedando cada vez más vacía en su afán por reproducir fotografías que "reducen la realidad del mundo a estereotipos que anulan la diversidad de los fenómenos a los que se refieren" (Baeza, 2001, p. 14). Pues tal como Fontcuberta (2003) sostiene, la invención de la fotografía es parte de la tradición pictórica renacentista abocada a la representación fiel respecto a la percepción visual humana, "paradójicamente la objetividad fotográfica iba a nacer de una exaltación más o menos encubierta de la subjetividad" (p. 18). Asimismo, Ritchin (2010), teórico y ex editor de fotografía de The New York Times, afirma que la fotografía, "al congelar y diseccionar lo visible en trozos discretos, ha tenido un rol importante en la creación de una representación de lo real, pero (...) también ha provocado una insidiosa distorsión de nuestra visión de lo real” (p. 12).

El debate entre la noción de fotografía vinculada a la mirada del fotógrafo y la fotografía como mero dispositivo de captura ha traído nuevas reflexiones. La fotografía de prensa con pretensiones miméticas, explica Ritchin (2010), 
se produce en un lenguaje cada vez más atrofiado, lo que desmonta la estética de la objetividad que se desmiente en las imágenes casi idénticas de los fotógrafos. Gran parte del fotoperiodismo reproduce fórmulas, explica el autor, "imágenes genéricas que conforman la jerga periodística: líder solemne, viuda afligida, niño desnutrido, explosión ardiente, etc.” (Ritchin, 2010, p. 30). Son códigos visuales y composiciones que están incorporadas en nuestra cultura visual a través del arte y de la cultura de masas. Para Ritchin, esta repetición de fórmulas visuales agrega ficción al acontecimiento retratado y lo teatraliza o, en palabras de Guy Debord, lo convierte en un espectáculo ${ }^{4}$. Se generan imágenes compositivamente asociadas con la significación simbólica de otras. Clichés visuales, según Georges Didi-Huberman, que solo pueden suscitar en la recepción clichés lingüísticos (2013, p. 16).

No es necesario que el fotógrafo altere la escena, basta con que tenga previamente en su imaginario la imagen que quiere conseguir. Como si un reportero al que envían a cubrir un conflicto armado ya supiera qué clase de imágenes espera el medio que lo contrata. El peso de estas ideas previas constituye clichés visuales que se pierden las especificidades del acontecimiento por consolidar una representación del mundo al que se accede de forma cada vez más mediática. "Deberíamos buscar la creación de imágenes más útiles y exploratorias, no solo las extravagantes y escandalosas", explica Ritchin (2010, p.14).

Siguiendo la línea de pensamiento de Ritchin, puede explicarse el auge de las imágenes amateur. No solo aportan inmediatez, sino que se presentan como registros espontáneos y cercanos a la experiencia de los usuarios. Así lo destacan algunos de los entrevistados cuando sostienen que la incorporación de imágenes de los usuarios aporta "inmediatez y cercanía” así como “participación y fidelización de los lectores” (M. Erramuspe, comunicación personal, noviembre 10, 2015); "adaptación del medio a la forma en que los usuarios consumen la información" (J. Frugoni, comunicación personal, noviembre 7,2015$)$ o "más vínculo con el lector” (F. Traibel, comunicación personal, noviembre 6, 2015). Son “imágenes urgentes" cuya producción parece haber dejado poco espacio a la puesta en escena y a la composición artificiosa. Su valor documental es proporcional a los signos de dispositivos domésticos, como celulares o iPads, así como de encuadres improvisados, contrastes poco controlados y otras marcas propias de una estética amateur, y sin estructura narrativa lógica o al menos no surgida de una reflexión.

Todas estas son señales de las que se infieren, de forma más o menos acertada, los modos y circunstancias de producción. En este sentido, el uso de nuevos formatos multimedia -videos, fotografías tomadas con teléfonos e incluso por usuarios-, tal como afirma el editor de Espectador.com, es un modo de adaptarse "a la forma en que los usuarios consumen la información” (J. Frugoni, comunicación personal, noviembre 7, 2015). En efecto, estudios recientes indican que este tipo de contenidos más desestructurados, como los videos de Youtube, tienen un gran número de visitas al incorporarse a medios de noticias (Mäenpää, 2014, p. 94). En este contexto en que se hace presente la sospecha de alejamiento de lo real por parte del fotoperiodismo, tal como lo expresa Ritchin, junto con la creciente aceptación por parte del público de las imágenes amateurs, algunos fotoperiodistas han desplegado acciones que fusionan la práctica tradicional con las nuevas posibilidades técnicas.

Algunas investigaciones sobre la identidad profesional de los fotorreporteros sugieren que ellos renegocian de forma constante los valores profesionales de su práctica, de acuerdo con el drástico cambio de su contexto de trabajo. Por ejemplo, al combinar las posibilidades digitales con su sentido de la ética y de su rol como garantes del interés público (Mäenpää, 2014, p. 101).
4:: Debord establece que el espectáculo es la irrealidad de la sociedad real: reproduce tan fielmente todos los signos de lo real que la representación se convierte en una puesta en escena. Su tesis $n .{ }^{\circ} 4$ se comprende de forma casi profética: "el espectáculo no es un conjunto de imágenes, sino una relación social entre personas mediatizada por imágenes" (Debord, 1998). 
Este es el caso de los profesionales que hacen uso de iPhones o de las redes sociales para generar coberturas más inmediatas y cercanas a los lectores. Las fotografías tomadas con celulares, para usarlas en real time en las redes y hasta videos producidos por los fotógrafos, "son un insumo vital y cada vez las utilizamos más”, explica Carina Novarese, editora multimedia de El Observador (comunicación personal, noviembre 7, 2015). Estos recursos intentan generar imágenes más auténticas, que no reflejen una realidad limpia y clara sino experiencias vivenciales. Según Pedro Meyer, para quien la imagen fiel es una falacia, una fotografía de refugiados $u$ otro acontecimiento "es cierta, con cámara o sin cámara, y por eso debemos enfocarnos en cuál es el planteamiento de la imagen; su veracidad debe estar centrada en la credibilidad del autor, no en el vehículo, la cámara" (Villarreal, 2014, p. 17). Desde este punto de vista, el fotógrafo tiene la posibilidad de hacer un uso propio de la herramienta y no uno codificado, como es el caso de las imágenes que muchos medios esperan obtener.

En esta línea, el pensamiento de Didi-Huberman (2013) permite reflexionar sobre cómo el peso de la objetividad -comprendida como la posibilidad de reproducción fiel de una realidad- no es condición para que una imagen sea considerada auténtica. Este autor sostiene que "las imágenes no son ni inmediatas, ni fáciles de entender” (p. 9), precisamente porque el hecho de que una imagen pueda transmitir lo real no quiere decir que "nos revela o nos ofrece univocamente la verdad sobre esa realidad" (p. 14). La imagen para este autor se propone como una instancia de desmaquillaje de lo real o, mejor dicho, desmaquillaje del espectáculo de lo real. Y en este proceso se produce un quiebre, "un malestar en la cultura visual" (p. 15), que poco a poco va fracturando la reproducción de las imágenes genéricas señaladas por Ritchin.

Es así que la pregunta por el estatus de representación de la realidad de la fotografía ya no se ocupa de la objetividad como el efecto-verdad que garantiza el valor documental de la imagen. En cambio, lo que en la actualidad parece otorgar a la imagen fotográfica su legitimidad como documento se relaciona mucho más con recursos formales originarios de una mirada subjetiva, aunque estrechamente relacionada con la realidad del acontecimiento que intenta plasmar. Si bien esto último forma parte de los valores éticos fundamentales de la profesión del fotoperiodista (Mäenpää, 2014, p. 102), en este momento parece reflejarse en las imágenes que adoptan recursos propios de la estética de aficionado.

Entre las consecuencias que las nuevas consideraciones acerca del valor documental de la fotografía han generado, la adopción de nuevos recursos formales que redefinen las estrategias mediales de representación de la realidad parece ser una de las más importantes. Se genera una recepción en la que se decodifica esta fotografía como una representación más cercana a lo real, lo cual a su vez está condicionado por recursos visuales y de producción relacionados con la práctica amateur.

Actualmente los lectores de La Diaria esperan cada día la foto que ilustra la noticia de tapa. Pasaba lo mismo en la década de los 90 con El Observador. Los lectores no requieren la información sobre el suceso, que de hecho tienen, sino que esperan el tratamiento visual que hace el periódico -aunque, para ser más justos, habría que decir que lo esperado es la mirada del 
fotógrafo-. En estos dos medios las fotografías trabajan en la hilaridad que ciertas miradas pueden descubrir en casi cualquier acontecimiento, y llegan al lector como un guiño cómplice, un regalo. Para Didi-Huberman (2013) una imagen que no es cliché visual es "una imagen que ha sabido desconcertar, después renovar nuestro lenguaje, y por tanto nuestro pensamiento" (p. 18). De esto se trata la mirada subjetiva que aporta en la fotografía las señas de autenticidad. Una dinámica que está detrás, solo en parte, de la incidencia de las imágenes amateurs en la fotografía profesional. Esto no quiere decir que toda imagen amateur tenga un valor informativo real.

En conclusión, la estética de cercanía, como estrategia mediática e incluso del fotógrafo profesional, ya forma parte del ámbito periodístico. Su desarrollo está relacionado con lo que puede entenderse como una crisis del estatus de la imagen profesional para representar la realidad, así como con las exigencias en la dinámica del flujo de información impuestas por las plataformas multimedia.

\section{Referencias}

Aguilar, Y. (2015, 21 de marzo). Me interesa la otra fotografía: Clément Chéroux. El Universal. Recuperado de: http:// confabulario.eluniversal.com.mx/me-interesa-la-otra-

fotografia-clement-cheroux/

Baeza, P. (2009, agosto). Fotografía documental: decreto de crisis. Le Monde Diplomatique en español, p.12.

Baeza, P. (2001). Por una función crítica de la fotografía de prensa. Barcelona: Gustavo Gili.

Barthes, R. (1990). La cámara lúcida. Nota sobre la fotografía. Barcelona: Paidós.

Cartier-Bresson, H. (1952). El instante decisivo. Fontcuberta, J. (Ed.). (2003). Estética fotográfica (pp. 221-236). Barcelona: Gustavo Gili.

Dubois, P. (1994). El acto fotográfico. De la representación a la recepción. Barcelona: Paidós.
Debord, G. (1998). La sociedad del espectáculo. Archivo Situacionista Hispano. Recuperado de: http://serbal.pntic.mec. es/ cmunoz11/Societe.pdf

Del Río, V. (2008). Fotografía objeto. La superación de la estética del documento. Salamanca: Ediciones Universidad de Salamanca.

Didi-Huberman, G. (2013). Cuando las imágenes tocan lo real. Didi-Huberman, G., Chéroux, C. y Arnaldo, J. Cuando las imágenes tocan lo real (pp. 9-36). Madrid: Círculo de Bellas Artes.

Fontcuberta, J. (Ed). (2003). Estética fotográfica. Barcelona: Gustavo Gili.

Ginart, B. (2001, 5 de noviembre). El fotoperiodismo entra en crisis. El País. Recuperado de http://elpais.com/diario/2001/11/05/cultura/1004914802_850215.html

Ledo, M. (1998). Documentalismo fotográfico. Madrid: Cátedra.

Mäenpää, J. (2014). Rethinking Photojournalism. The Changing Work Practices and Professionalism of Photojournalists in the Digital Age. Nordicom Review,35, 2, 91-104.

Minervini, M. y Pedrazzini, A. (2004). El protagonismo de la imagen en la prensa. Revista Latina de Comunicación, 58, 1-4. Recuperado de http://www.ull.es/publicaciones/latina/ 20042058minervini.pdf

Porciúncula, P. (2010). Reportaje fotográfico en soporte multimedia [Memoria de Grado]. Montevideo: Universidad Católica del Uruguay.

Ritchin, F. (2010). Después de la fotografía. México: Océano.

Scott, G. (2015). Professional Photography. The new global landscape explained. Nueva York: Focal Press.

Villarreal, R. (2014). "La fotografía tiene un lugar central en la cultura contemporánea y por eso debemos enseñar a leer imágenes": Entrevista con Pedro Meyer, fotógrafo. Magis, 440, 10-17.

Zhang, M. (2015, 18 de noviembre). Reuters Issues a Worldwide Ban on RAW Photos. Petapixel. Recuperado de http://petapixel.com/2015/11/18/reuters-issues-a-worldwide-banon-raw-photos/

DOI: http://dx.doi.org/10.22235/d.v0i25.1270 